\title{
Fibroblast Growth Factor-2 Enhances Extinction and Reduces Renewal of Conditioned Fear
}

\author{
Bronwyn M Graham*,' and Rick Richardson' \\ 'School of Psychology, The University of New South Wales, Sydney, NSW, Australia
}

Anxiety disorders are increasingly prevalent in society; hence, there is a need to improve on existing treatments for such disorders. Fibroblast growth factor-2 (FGF2), a mitogen that is involved in brain development and regeneration, has been shown to both facilitate long-term extinction of fear and reduce stress-precipitated relapse in rats. Extinction is the laboratory analog of exposure-based therapies in humans. In this study, we continued to investigate the clinical potential of FGF2 as a pharmacological enhancer of extinction by examining its effect on renewal, a common type of relapse. In all experiments, rats were trained to fear a white noise-conditioned stimulus, and then this learned fear was extinguished the following day. Rats received systemic injections of FGF2 or vehicle immediately after extinction training. At test, on the day after extinction training, levels of freezing elicited by the white noise in either the extinction context or the original training context were measured. FGF2-treated rats showed less renewal of fear when tested in the original training context than did vehicle-treated rats. This pattern occurred even when vehicle rats were given double the amount of extinction training, and when FGF2-treated rats were given equivalent exposure to the extinction context. These results show that FGF2 facilitates long-term extinction and attenuates relapse, and thus highlight its potential as a novel pharmacological adjunct to exposure therapy. Neuropsychopharmacology (2010) 35, 1348-1355; doi:I0.1038/npp.2010.3; published online 3 February 2010

Keywords: fibroblast growth factor-2; fear extinction; renewal; rat

\section{INTRODUCTION}

Anxiety disorders are placing an increasingly large burden on society, and the World Health Organization (2001) predicts that by the year 2020 anxiety disorders will be among the top two most burdensome illnesses in the world. Exposure therapy is the most widely used, and empirically supported, treatment for anxiety, and involves the repeated presentation of the feared stimulus or outcome in the absence of any danger. However, exposure therapy is not without its pitfalls; a high dropout rate and failure to maintain treatment gains (ie, relapse) are among its limitations (McNally, 2007). Hence, there is a need to improve existing treatments for anxiety.

Exposure therapy is based on fear extinction, which is the most common procedure for investigating inhibition of fear in the laboratory. Recently, extensive work has shed increasing light on the behavioral and molecular mechanisms underlying extinction (for reviews, see Quirk and Mueller, 2008; Bouton et al, 2006). It is now widely accepted that extinction, at least in part, involves new learning. This

*Correspondence: BM Graham, School of Psychology, The University of New South Wales, Sydney, NSW 2052, Australia,

Tel: + 61-2-93851813, Fax: + 61-2-9385364l,

E-mail: bgraham@psy.unsw.edu.au

Received 2 October 2009; revised 5 January 20 I0; accepted 6 January 2010 is because several manipulations can lead to a return of fear following extinction. For example, fear of an extinguished cue typically returns following the presentation of a mild, unsignaled stressor, a phenomenon termed 'reinstatement' (Bouton and Bolles, 1979a). Furthermore, fear typically returns to an extinguished cue when it is presented in a different context to that in which extinction occurred, a phenomenon termed 'renewal' (Bouton and Bolles, 1979b). In addition to providing insight into the behavioral mechanisms underlying extinction, both reinstatement and renewal are recognized as useful laboratory analogs of relapse after exposure therapy.

Given that extinction involves new learning, recently research has started to investigate potential pharmacological adjuncts that may enhance the learning and memory processes underlying extinction. The most successful of these has been d-cycloserine (DCS), a partial N-methyl-Daspartate receptor agonist that has been shown to enhance extinction in rats (Walker et al, 2002; Ledgerwood et al, 2003) and exposure therapy in humans with social phobia (Hofmann et al, 2006; Guastella et al, 2008), obsessive compulsive disorder (Kushner et al, 2007), and acrophobia (Ressler et al, 2004). One attractive feature of DCS is that it has been shown to reduce reinstatement (Ledgerwood et al, 2004). However, there are several potential problems with DCS, including the findings that repeated administration of DCS (Parnas et al, 2005) or chronic pre-exposure to the antidepressant imipramine (Werner-Seidler and Richardson, 
2007), both prevent the enhancement of extinction by DCS in rats. Furthermore, despite reducing reinstatement, DCS has been shown to have no effect on renewal (Woods and Bouton, 2006). Therefore, despite its clinical promise, DCS shows some limitations.

We recently proposed that fibroblast growth factor-2 (FGF2) may be another novel pharmacological adjunct to exposure therapy. FGF2 is part of a large family of neurotrophic molecules that is involved in brain development (Walicke et al, 1986), adult neurogenesis (Wagner et al, 1999), and regenerative plasticity (Gomez-Pinilla et al, 1995). Furthermore, FGF2 affects the molecular cascade involved in learning and memory (Graham and Richardson, 2009a), and therefore acute FGF2 should enhance extinction of learned fear. Indeed, we have recently demonstrated that FGF2 administration does enhance long-term extinction of learned fear in rats, and further, that FGF2-treated rats are less susceptible to reinstatement, even when control rats were given double the amount of extinction training to equate levels of fear after extinction (Graham and Richardson, 2009b).

These findings suggest that FGF2 has clinical potential, but one question that arises from these findings is with regard to the mechanism by which FGF2 facilitates extinction. The most widely accepted account of extinction purports that the extinction memory is context dependent, such that the animal only retrieves and expresses the extinction memory in the context in which extinction training occurred (Bouton, 2002). In other words, the animal learns that the feared cue is safe only in the extinction context. Given that we have shown that FGF2 enhances memory for contexts (Graham and Richardson, 2009a), it is possible that FGF2 enhances extinction by facilitating the memory of the extinction context as a 'safe' environment, such that when rats are presented the cue in that context, they more easily retrieve the extinction memory. This explanation would also account for the finding that FGF2 reduces reinstatement. During this procedure, rats are exposed to a stressor (eg, a mild footshock) after extinction. Typically, when tested with the extinguished cue the following day, rats show recovered levels of fear (ie, relapse). Previous research has shown that during reinstatement, the stressor becomes associated with the context and that when rats are subsequently presented the extinguished cue in that context, the context triggers a recovery of fear for that cue (Bouton and Bolles, 1979b). If FGF2 enhances inhibitory learning about the context during extinction (ie, learning that the context is a 'safe' place), then it will likely impede the formation of this contextstressor association, thereby rendering FGF2-treated rats less susceptible to reinstatement.

If FGF2 facilitates extinction by enhancing inhibitory learning about the extinction context, then it should be the case that FGF2-treated rats show recovery of conditioned fear when tested in a different context to that in which extinction took place (ie, they should show renewal). In the current series of experiments, we investigated this possibility. Experiment 1 replicated our previous findings that FGF2 enhances extinction, as well as determining the smallest possible effective dose of FGF2. Experiment 2 investigated renewal in FGF2- and vehicle-treated rats, with the vehicle-treated animals given double the amount of extinction to equate the strength of extinction between the two conditions. Experiment 3 was similar to Experiment 2, with the exception that FGF2-treated rats were given additional exposure to the extinction context to equate the time spent in the extinction context between vehicle- and FGF2-treated rats. These experiments are of theoretical and practical importance, as the results provide insight into the mechanisms by which FGF2 enhances extinction as well as exploring the potential limitations of using FGF2 as a novel pharmacological adjunct to exposure therapy.

\section{MATERIALS AND METHODS}

\section{Subjects}

Experimentally naive Sprague Dawley-derived rats, bred and housed in the School of Psychology, The University of New South Wales, were used. Rats were $23( \pm 1)$ days of age at the start of all experiments. Rats at this age show adultlike extinction behavior (Kim and Richardson, 2008). All rats were male, and no more than one rat per litter was used per group. Rats were housed with their littermates and mother in plastic boxes $(24.5 \mathrm{~cm}$ long $\times 37 \mathrm{~cm}$ wide $\times$ $27 \mathrm{~cm}$ high) covered by a wire lid. Animals were maintained on a $12 \mathrm{~h}$ light/dark cycle (lights on at 0600 hours) with food and water available ad libitum. Animals were treated according to the principles of animal use outlined in The Australian Code of Practice for the Care and Use of Animals for Scientific Purposes (Seventh Edition), and all procedures were approved by the Animal Care and Ethics Committee at The University of New South Wales.

\section{Drug}

Rats were injected subcutaneously in the dorsal neck region with either vehicle or FGF2. In all experiments, FGF2 (R\&D Systems) was reconstituted at a concentration of $10 \mu \mathrm{g} / \mathrm{ml}$ in phosphate-buffered serum (PBS) containing $0.1 \%$ bovine serum albumin (BSA). The vehicle was PBS containing $0.1 \%$ BSA. Vehicle was administered in a volume of $0.002 \mathrm{ml} / \mathrm{g}$ of body weight in all three experiments; FGF2 was also administered in a volume of $0.002 \mathrm{ml} / \mathrm{g}$ of body weight in Experiments 2 and 3 (yielding a dose of $20 \mathrm{ng} / \mathrm{g}$ of body weight). As Experiment 1 involved examining the smallest effective dose required for the FGF2 enhancement of extinction, rats were injected with a volume of 0.002 , 0.001 , or $0.0005 \mathrm{ml} / \mathrm{g}$ of body weight (yielding doses of 20 , 10 , and $5 \mathrm{ng} / \mathrm{g}$ of body weight, respectively).

\section{Apparatus}

Two types of chambers were used to provide different contexts. One type was rectangular $(13.5 \mathrm{~cm}$ long $\times 9 \mathrm{~cm}$ wide $\times 9 \mathrm{~cm}$ high), with the front wall, rear wall, and ceiling constructed of clear Plexiglas. The floor and sidewalls of these chambers consisted of $3 \mathrm{~mm}$ stainless steel rods set $1 \mathrm{~cm}$ apart. These chambers were housed within wood cabinets so that external noise and visual stimulation were minimized. A white LED and an infrared light were the sole sources of illumination in these chambers (referred to as Context $\mathrm{A}$ hereafter). 
The second type of chamber was rectangular $(30 \mathrm{~cm}$ long $\times 30 \mathrm{~cm}$ wide $\times 23 \mathrm{~cm}$ high) and wholly constructed of Plexiglas, with the exception of the grid floor that was the same as in the first type of chamber. The walls were transparent, except for two sidewalls that consisted of vertical black and white stripes $(5 \mathrm{~cm}$ each). Instead of bedding, a sheet of Plexiglas $(35 \mathrm{~cm} \times 35 \mathrm{~cm})$ was placed beneath the grid floor. These chambers were housed in wood cabinets so that external noise and visual stimulation were minimized. A white LED and an infrared light were the sole sources of illumination in these chambers (referred to as Context B hereafter). Thus, these two sets of contexts differed primarily in terms of their size and in their visual features.

In Experiment 1, all rats were trained in Context $A$, and extinguished and tested in Context B. In Experiment 2, half the rats were trained in Context $\mathrm{A}$ and extinguished and tested in Context $\mathrm{B}$, or trained in Context $\mathrm{B}$ and extinguished and tested in Context $\mathrm{A}$ (ie, $\mathrm{ABB}$ or $\mathrm{BAA}$; groups same). The other half were trained in Context $A$, extinguished in Context $\mathrm{B}$, and tested in Context $\mathrm{A}$, or trained in Context $B$, extinguished in Context $A$, and tested in Context B (ie, $\mathrm{ABA}$ or BAB; groups different). As there were no differences between the counterbalanced same and different conditions in Experiment 2, in Experiment 3 rats were trained and extinguished in Contexts $\mathrm{A}$ and $\mathrm{B}$, respectively, and then tested in Context A (group same) or Context B (group different).

The conditioned stimulus (CS) was a white noise; noise level in the chambers was increased by $8 \mathrm{~dB}$ when the CS was presented. The unconditioned stimulus (US) was a $0.6 \mathrm{~mA}, 1.0 \mathrm{~s}$ footshock. A computer controlled all presentations of the CS and the US.

\section{Procedure}

Training. Training was identical in all experiments. On day 1 , rats received three pairings of the white-noise CS and the footshock US. Rats were placed in the conditioning chamber, and after a 2-min adaptation period the CS was presented for $10 \mathrm{~s}$ and co-terminated with the shock US. The inter-trial interval (ITI) ranged from 85 to $135 \mathrm{~s}$ with a mean of $110 \mathrm{~s}$. Thirty to sixty seconds after the third pairing rats were returned to their home cages.

Extinction. On day 2 in Experiment 1, all rats received 15 non-reinforced presentations of the CS. After a 2-min adaptation period, the $10 \mathrm{~s}$ CS was presented with a $10 \mathrm{~s}$ ITI. Thirty to sixty seconds after the last extinction trial, rats were injected (with FGF2 or vehicle) and then returned to their home cages. In Experiments 2 and 3, we attempted to equate the levels of freezing at test in the vehicle- and FGF2treated rats in the same condition; this needed to be performed to allow for meaningful conclusions about the effect of FGF2 on renewal. Therefore, during extinction on day 2 in Experiments 2 and 3, the vehicle rats received 30 non-reinforced CS presentations (10 s CS with a $10 \mathrm{~s} \mathrm{ITI),}$ whereas the FGF2 rats received 15 non-reinforced CS presentations. Rats were injected 30-60 s after the last extinction trial. Experiment 3 had the same design as Experiment 2, except that the FGF2-treated rats remained in the extinction context for $5 \mathrm{~min}$ after the last extinction trial. This extra 5 min equated the amount of exposure to the extinction context across the two conditions. Thirty to sixty seconds after being removed from the extinction context, all rats were injected (with vehicle or FGF2).

Test. On day 3 in all experiments, rats were tested for CSelicited freezing. Pre-CS freezing was recorded for $1 \mathrm{~min}$ and then the CS was presented for $2 \mathrm{~min}$. CS-elicited freezing is difficult to detect if rats display high pre-CS levels of freezing. Therefore, a baseline criterion was introduced. Specifically, if a rat was freezing more than $50 \%$ of the pre-CS period at test, it was removed from the test chamber without the CS being presented and returned to its home cage. After 5-10 min, the rat was returned to the test chamber for a second test of pre-CS freezing. This was repeated until the pre-CS level of freezing was less than 50\% or until three pre-CS freezing tests had been conducted. One rat from the FGF2-different group in Experiment 3 did not meet the baseline criterion and so was not tested. Three rats from the vehicle-different group in Experiment 3 had to be returned to the test chamber once during testing. (The statistical results for this experiment were the same regardless of whether these rats were included in the analysis or not.)

\section{Scoring and Statistics}

Each animal was scored for freezing during extinction training and test. Freezing was scored by a time sampling procedure, whereby each rat was scored every $3 \mathrm{~s}$ as freezing or not freezing. Freezing was defined as the absence of all movement other than those required for respiration (Fanselow, 1980). A percentage score was calculated for each animal to determine the proportion of total observations scored as freezing. Extinction data were collapsed across trials to produce blocks of extinction (each block consisting of three trials). The scorer was unaware of the condition of the rats.

\section{RESULTS}

\section{Experiment 1: Dose-Response}

Table 1 presents the mean pre-CS freezing before extinction and test. A one-way ANOVA revealed that there were no significant differences between groups in levels of pre-CS freezing before extinction or test (both $\mathrm{Fs}<1$ ). A group (vehicle, FGF2-5, FGF2-10, or FGF2-20) by extinction block mixed-design ANOVA of the extinction data (Figure 1a) yielded a significant effect of block $\left(\mathrm{F}_{(4,180)},=14.45\right.$, $p<0.0001$ ), due to freezing levels decreasing across blocks. Furthermore, there was no significant effect of group $(\mathrm{F}<2.6)$, and no group by extinction trial interaction $(\mathrm{F}<1)$, meaning that all groups showed similar levels of conditioned fear and similar rates of extinction. This is as would be expected given that extinction occurred before any injections. Freezing to the CS at test is shown in Figure 1b. A one-way ANOVA revealed a significant effect of group $\left(\mathrm{F}_{(3,48)}=5.06, p<0.004\right)$. Subsequent post hoc comparisons using Tukey's honestly significantly differences test revealed that rats given FGF2 at a dose of $20 \mathrm{ng} / \mathrm{g}$ of body weight immediately after extinction showed significantly less 
CS-elicited freezing at test than did the rats in the other three groups (largest $p<0.016$ ), which did not differ. To confirm that we replicated the finding that $20 \mathrm{ng} / \mathrm{g}$ of body weight dose of FGF2 facilitates long-term extinction, we performed follow-up analyses comparing the within-session extinction and extinction test performance of FGF2-20 rats and vehicle-treated rats. An independent samples $t$-test confirmed that there was no difference between FGF2-20 and

Table I Mean $( \pm$ SEM) Pre-CS Percent Freezing Before Extinction and Before Test for all Experiments

\begin{tabular}{lcccc}
\hline Experiment & \multicolumn{4}{c}{ Group } \\
\hline Experiment I & Vehicle & FGF2-5 & FGF2-10 & FGF2-20 \\
Extinction & $13.6(2.9)$ & $12.9(4.3)$ & $18.3(3.3)$ & $18.7(5.6)$ \\
Test & $12.9(6.3)$ & $7.9(3)$ & I3.I (4.I) & $7.1(2.7)$ \\
& & & & \\
Experiment 2 & Vehicle-same & FGF2-same & Vehicle-different & FGF2-different \\
Extinction & $17.8(8.4)$ & $24.2(6.7)$ & $19.4(7.5)$ & $16.9(5.9)$ \\
Test & $2.9(1.7)$ & $10.8(4.2)$ & $5.9(2.9)$ & $10(3.4)$ \\
& & & & \\
Experiment 3 & Vehicle-same & FGF2-same & Vehicle-different & FGF2-different \\
Extinction & $3.57(4.3)$ & $10.5(3.4)$ & $2.6(1.5)$ & $10.7(4)$ \\
Test & $2.5(1.3)$ & $6.3(3.6)^{\mathrm{a}}$ & II.3 (3.5) & $28.6(5.1)^{\mathrm{a}, \mathrm{b}}$ \\
\hline
\end{tabular}

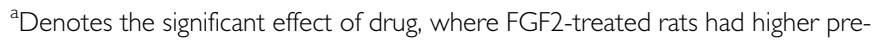
CS freezing than vehicle-treated rats.

${ }^{b}$ Denotes the significant effect of context, where rats tested in a different context to that of extinction had higher pre-CS freezing than rats tested in the extinction context. vehicle-treated rats during the first block of extinction $\left(t_{(22)}=0.91\right)$, or during the last block of extinction $\left(t_{(22)}=0\right)$, meaning that both groups showed similar levels of conditioned fear and similar rates of extinction. Furthermore, an independent samples $t$-test confirmed a significant difference between FGF2- and vehicle-treated rats at test $\left(t_{(22)}=3.10, p=0.005\right)$. Therefore, we replicated the finding that FGF2 facilitates long-term extinction and in addition demonstrated that, in this preparation, FGF2 needs to be administered at a dose no less than $20 \mathrm{ng} / \mathrm{g}$ of body weight to be effective.

\section{Experiment 2: Effect of FGF2 on Renewal}

A $2 \times 2$ ANOVA, where the first factor was drug (vehicle or FGF2) and the second factor was extinction context (same or different) revealed no significant effect of drug or extinction context, or a drug-by-extinction context interaction, on levels of pre-CS freezing before extinction or test (Fs $<3.3$; see Table 1 for means). Freezing levels during extinction are presented in Figure 2a. As the vehicle rats received 30 extinction trials and the FGF2 rats received 15 extinction trials, only the first 15 trials during extinction were analyzed. There was a significant effect of trial $\left(\mathrm{F}_{(4,176)},=20.00, p<0.0001\right)$, as the level of freezing decreased across trials. There was no main effect of drug or extinction context (Fs $<1)$, and no significant drug-byextinction context interaction $(\mathrm{F}<1.4)$, meaning that all groups showed similar levels of conditioned fear and similar rates of extinction. To confirm the lack of group differences in fear acquisition and fear extinction, we performed subsequent analyses on the first and last blocks of
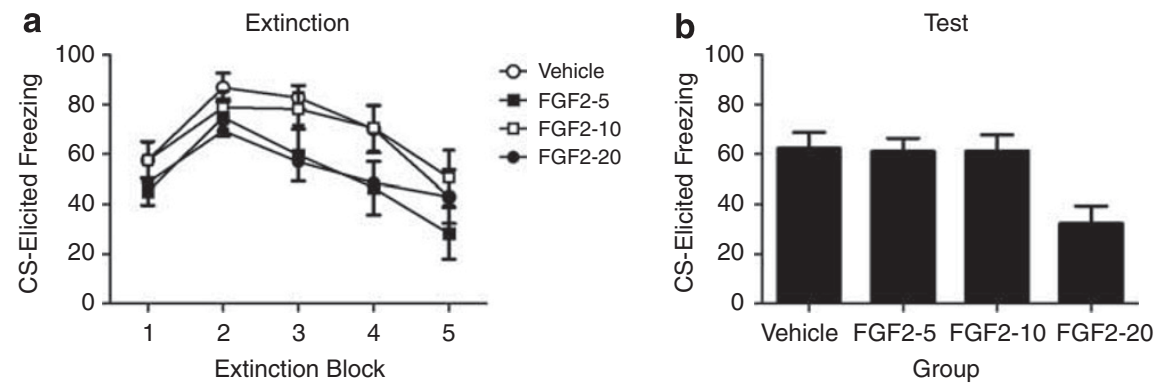

Figure I (a) Mean ( \pm SEM) freezing by rats in response to the CS during extinction training in Experiment I. (b) Mean ( \pm SEM) CS-elicited freezing by rats during test in Experiment I. Rats had been injected with vehicle $(n=12)$, or $5(n=12), 10(n=13)$, or 20 ( $n=12)$ ng/g body weight FGF2 after extinction training.
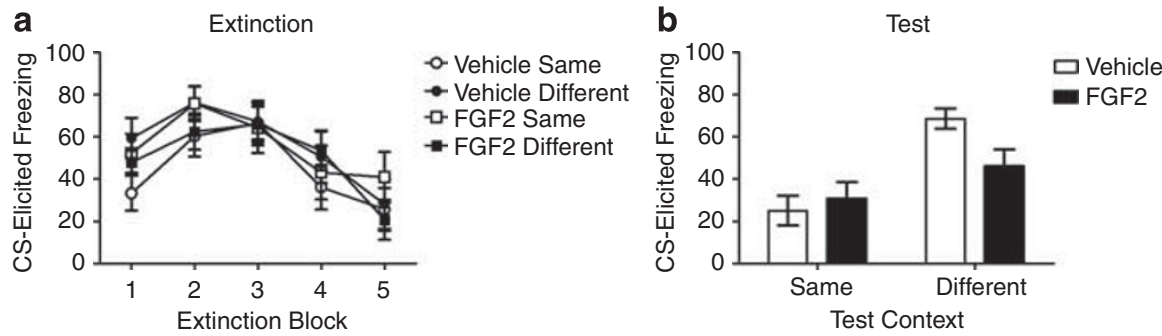

Figure 2 (a) Mean ( \pm SEM) CS-elicited freezing by vehicle- and FGF2-treated rats in response to the CS during extinction training in Experiment 2. Some of these rats were subsequently tested in the same context (vehicle-treated: $n=12$; FGF2-treated: $n=11$ ) whereas others were tested in a different context (vehicle-treated: $n=13$, FGF2-treated: $n=12$ ). Vehicle-treated rats received an additional 15 extinction trials during extinction training compared with FGF2-treated rats (data not shown). (b) Mean ( \pm SEM) freezing by rats in response to the CS during test in Experiment 2. 

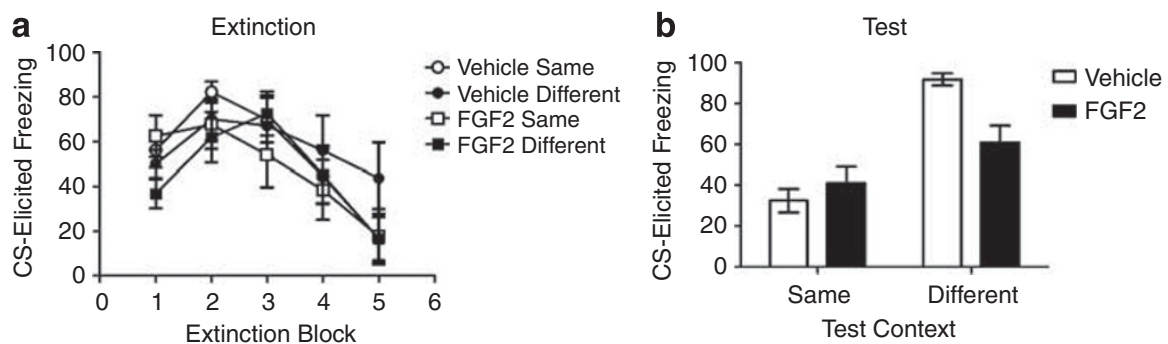

Figure 3 (a) Mean $( \pm$ SEM) CS-elicited freezing by vehicle- and FGF2-treated rats in response to the CS during extinction training in Experiment 3. Some of these rats were subsequently tested in the same context (vehicle-treated: $n=8$; FGF2-treated: $n=8$ ), whereas others were tested in a different context (vehicle-treated: $n=8$, FGF2-treated: $n=7$ ). Vehicle-treated rats received an additional 15 extinction trials during extinction training compared with FGF2-treated rats (data not shown). (b) Mean ( \pm SEM) freezing by rats in response to the CS during test in Experiment 3.

extinction. A $2 \times 2$ ANOVA revealed no significant effect of drug or extinction context, or a drug-by-extinction context interaction on levels of freezing during the first block of extinction $(\mathrm{Fs}<3.3)$, or the last block of extinction (Fs $<1.06$ ).

Freezing levels at test are shown in Figure $2 \mathrm{~b}$. There was a significant main effect of extinction context $\left(\mathrm{F}_{(1,44)}=18.16\right.$, $p<0.0001$ ), with rats tested in a context different from that where extinction occurred showing significantly more CS-elicited freezing than rats tested in the extinction context. There was no effect of drug $(\mathrm{F}<1.4)$, but there was a significant drug-by-extinction context interaction $\left(\mathrm{F}_{(1,44)}=4.20, p<0.046\right)$. This interaction was due to FGF2-treated rats tested in a context different from the extinction context showing significantly lower levels of fear than vehicle-treated rats tested in the different context $\left.t_{(23)}=2.42, p=0.026\right)$, whereas rats tested in the extinction context showed comparable levels of fear regardless of drug condition $\left(t_{(21)}=0.55, p=0.56\right)$. Therefore, Experiment 2 demonstrated that FGF2 significantly reduced renewal after extinction, even when the levels of CS-elicited freezing in the vehicle and FGF2-treated rats tested in the extinction context were equated.

\section{Experiment 3: Effect of FGF2 on Renewal when Time Spent in the Extinction Context is Equated}

A $2 \times 2$ ANOVA, where the first factor was drug (vehicle or FGF2) and the second factor was extinction context (same or different) revealed no significant effect of drug or extinction context, or a drug-by-extinction context interaction, on levels of pre-CS freezing before extinction (Fs $<3.7$; see Table 1 for means). Freezing levels during extinction are presented in Figure $3 \mathrm{a}$. As the vehicle rats received 30 extinction trials and the FGF2 rats received 15 extinction trials, only the first 15 trials during extinction were analyzed. There was a significant effect of trial $\left(\mathrm{F}_{(4,108)}=16.68, p<0.0001\right)$, with the level of freezing decreasing across trials. There was no effect of drug or extinction context, nor a significant drug-by-extinction context interaction $(\mathrm{Fs}<1.2)$, meaning that all groups showed similar levels of conditioned fear and similar rates of extinction. To confirm the lack of group differences in fear acquisition and fear extinction, we performed subsequent analyses on the first and last blocks of extinction. A $2 \times 2$ ANOVA revealed no effect of drug $(\mathrm{F}<1)$, but a significant effect of extinction context $\left(\mathrm{F}_{(1,27)}=4.3\right.$, $p=0.048)$ on levels of freezing during the first block of extinction. This means that rats that were subsequently tested in the different context froze slightly less during the first block of extinction. Importantly, there was no drug-byextinction context interaction on levels of freezing during the first block of extinction $(\mathrm{F}<3.3)$, and no difference between vehicle-different and FGF2-different rats during the first block of extinction. Furthermore, there was no effect of drug, context, or a drug-by-extinction context interaction on levels of freezing during the last block of extinction (Fs $<1.3$ ), meaning that all groups extinguished to the same level after extinction training. Although there is an apparent difference in freezing levels between vehicle-different and FGF2-different rats during the first block of extinction, this difference is not statistically significant $\left(t_{(13)}=1.44\right.$, $p=0.17)$ and is driven by two rats that froze at $\sim 16 \%$ during the first block of extinction. (The statistical results were the same when these rats were excluded from the analysis.) Furthermore, the mean level of freezing in both groups increases by the second extinction block, during which the mean levels of freezing are comparable between the two groups. Thus, the differences observed at test are not due to apparent differences in levels of fear during the extinction session between these two groups.

A $2 \times 2$ ANOVA, where the first factor was drug (vehicle or FGF2) and the second factor was extinction context (same or different) revealed a significant effect of drug $\left(\mathrm{F}_{(1,27)}=8.86, p=0.006\right)$ and extinction context $\left(\mathrm{F}_{(1,27)}=19.28\right.$, $p=0.001$ ) on levels of pre-CS freezing before test, with rats tested in the different context showing significantly higher levels of pre-CS freezing at test, and FGF2-treated rats showed significantly higher levels of pre-CS freezing at test. There was no significant drug-by-extinction context interaction $(\mathrm{F}<3.7)$. To control for these differences in pre-CS freezing, an analysis of covariance (ANCOVA) was conducted of the test data, using pre-CS freezing scores as the covariate. (The statistical results were the same when an ANOVA was used.) Freezing levels at test are shown in Figure $3 \mathrm{~b}$. The ANCOVA revealed a significant main effect of extinction context $\left(\mathrm{F}_{(1,26)}=18.56, p<0.0001\right)$, with rats tested in a context different from extinction showing significantly more CS-elicited freezing than rats tested in the extinction context. There was no effect of drug $(\mathrm{F}<2.7)$, but there was a significant drug-by-extinction context interaction $\left(\mathrm{F}_{(1,26)}=8.30, p=0.008\right)$. This 
interaction was due to FGF2-treated rats tested in a context different from extinction showing significantly lower levels of fear than vehicle-treated rats tested in the different context $\left(t_{(13)}=3.54, p=0.008\right)$, whereas rats tested in the extinction context showed comparable levels of fear regardless of drug condition $\left(t_{(14)}=0.88\right)$. Therefore, Experiment 3 replicated the finding of Experiment 2 that FGF2 significantly reduced renewal after extinction, even when the levels of CS-elicited freezing in the vehicle- and FGF2-treated rats tested in the extinction context were equated. Furthermore, Experiment 3 demonstrated that FGF2 significantly reduced renewal after extinction even when the time spent in the extinction context was equated between FGF2- and vehicle-treated rats.

\section{DISCUSSION}

The present experiments replicate our previous findings that FGF2 facilitates long-term extinction (Experiment 1), and extends our previous findings by demonstrating that FGF2 also attenuates return of fear when rats are tested in a different context to that of extinction (ie, renewal is reduced in FGF2-treated rats; Experiments 2 and 3). The finding that FGF2 reduces renewal cannot be attributed to FGF2-treated rats having lower levels of fear at test than vehicle rats because the vehicle rats were given double the amount of extinction, and thus showed comparable levels of extinction to the FGF2-treated rats when tested in the extinction context. The fact that vehicle rats received double the amount of extinction meant that in Experiment 2 vehicle rats spent more time in the extinction context (and thus had more time to encode a representation of the context) than FGF2 rats. Therefore, it is possible that FGF2-treated rats showed less renewal because they were less able to discriminate between the extinction and training contexts in comparison with the vehicle rats. However, this explanation is unlikely because FGF2 has been shown to facilitate long-term memory for contexts (and thus the FGF2-treated rats should not be disadvantaged by spending less time in the extinction context; Graham and Richardson, 2009a). Nevertheless, Experiment 3 tested this possibility by giving FGF2-treated rats additional context exposure after extinction, thus equating the time spent in the extinction context between the vehicle- and FGF2-treated rats. The results of Experiment 3 replicated those of Experiment 2 in showing that FGF2 reduces renewal of conditioned fear, even when all rats are given equivalent context exposure. Finally, these results cannot be attributed to FGF2 affecting locomotion, as FGF2 was administered after extinction training (and thus was not present during within-session extinction), and rats were tested $24 \mathrm{~h}$ after the FGF2 injection (at which point FGF2 would no longer be present).

Together, these experiments address and raise important questions regarding the mechanisms by which FGF2 facilitates extinction. The results of these experiments were surprising as they suggest that FGF2 does not merely enhance 'normal' extinction processes (ie, new learning that is context dependent). If this were the case, then FGF2treated rats should show renewal of fear when tested in a context different to that where extinction occurred. Yet, the results of Experiments 2 and 3 clearly show that FGF2treated rats are less susceptible to renewal. This finding, while surprising in one regard, does fit with our previous demonstration that FGF2-treated rats were less susceptible to reinstatement of an extinguished fear response (Graham and Richardson, 2009b). That is, taken together, these results show that FGF2-treated rats are less susceptible to common forms of relapse.

Our previous experiments have demonstrated that FGF2 must be combined with at least 15 extinction trials to facilitate long-term extinction, and that FGF2 is not effective when combined with only five extinction trials (Graham and Richardson, 2009b). This demonstrates that FGF2 is modulating some aspect of the extinction process to facilitate long-term extinction. Therefore, in light of the present experiments, there are two broad possible mechanisms by which FGF2 may facilitate extinction. The first is that FGF2 may alter the extinction memory, most likely by facilitating context-independent new learning (ie, producing generalized extinction). Indeed, several behavioral manipulations have been shown to produce contextindependent extinction. For example, conducting extinction in multiple contexts (Gunther et al, 1998), and conducting extinction training and testing in the presence of a discrete cue (Brooks and Bouton, 1994), both lead to a reduction in renewal. However, the molecular mechanisms by which FGF2 may lead to context-independent new learning remain unclear.

The other mechanism by which FGF2 may facilitate extinction is by altering the original fear memory, perhaps by enhancing the incorporation of the CS-no US memory into the reconsolidation of the original fear memory, or by causing erasure of the original fear memory. Although it is widely accepted that extinction involves new learning, several authors have argued that extinction likely involves multiple processes, including some erasure of the original fear memory (for a review, see Myers and Davis, 2007). The main evidence for this is that recovery of fear after reinstatement or renewal is rarely complete. In addition, recent research has indicated that reconsolidation of the original fear memory may also have a role in extinction, as conducting extinction training shortly after reactivating the original fear memory has been shown to reduce renewal and reinstatement (Monfils et al, 2009). Our findings that FGF2 reduces relapse are consistent with both of these theoretical accounts of extinction (ie, reconsolidation and erasure). Although the molecular mechanisms by which FGF2 may alter the reconsolidation of the original fear memory are unclear, there is preliminary evidence that long-term depotentiation (the molecular phenomenon that has been proposed to underlie memory erasure) is associated with an increase in neurotrophic factors (Yuzaki et al, 1994). Given the evidence that FGF2 mediates synaptic plasticity, and that long-term depotentiation is a form of synaptic plasticity, it is possible that FGF2 may also be involved in regulating long-term depotentiation, and thus may enhance erasure of the original fear memory after extinction training. This explanation is admittedly speculative, and further research investigating the molecular mechanisms by which FGF2 facilitates extinction, including the neural substrates that mediate this effect, is required to address these possibilities. 
Nonetheless, these findings are of clinical interest. Previous research has suggested that FGF2 may be of clinical relevance to a variety of disorders, including heart disease and depression. For example, FGF2 has previously been trialed in humans as a potential inducer of angiogenesis (Lederman et al, 2002). Furthermore, recent research has demonstrated that chronic administration of FGF2 reduces anxiety and depressive-like behavior in rats (Perez et al, 2009; Turner et al, 2008). However, we are the first to propose its use as a novel pharmacological adjunct to exposure therapy (Graham and Richardson, 2009b). The present experiments, coupled with our previous findings, highlight at least two potential benefits to using FGF2 in this way. First, Experiments 2 and 3 demonstrate that extinction combined with FGF2 is as effective as double the amount of extinction without FGF2 (also see Graham and Richardson, 2009b). As exposure therapy is time-consuming and requires extensive commitment from the patient, the finding that FGF2 produces equivalent results in half the amount of time suggests that it may improve the efficiency of exposure therapy, which may reduce treatment dropout rates. The second benefit relates to our findings that FGF2 reduces two common types of relapse: stress-precipitated reinstatement (Graham and Richardson, 2009b) and renewal (the present study). Renewal is a robust effect both in the laboratory and in clinical settings (Mineka et al, 1999; Mystkowski et al, 2002). Furthermore, in a longitudinal study of the clinical course of anxiety disorders over 12 years, it was demonstrated that anxiety disorders have a largely chronic course with low recovery rates and high relapse rates (Bruce et al, 2005). This illustrates the need to target relapse rates in treatment; thus, the findings that FGF2 renders rats less susceptible to relapse are potentially clinically relevant.

\section{ACKNOWLEDGEMENTS}

This research was supported by Discovery Project grants from the Australian Research Council (DP0346139 and DP0666953) to Rick Richardson and an Australian Postgraduate Award to Bronwyn Graham.

\section{DISCLOSURE}

The authors declare that, except for the income received from the primary employers and ARC grants listed in the 'Acknowledgements' section, no financial compensation was received from any individual or corporate entity over the past 3 years of research or professional service that could be perceived as constituting a potential conflict of interest.

\section{REFERENCES}

Bouton M (2002). Context, ambiguity, and unlearning: sources of relapse after behavioral extinction. Biol Psychiatry 52: 976-986.

Bouton ME, Bolles RC (1979a). Role of conditioned contextual stimuli in reinstatement of extinguished fear. J Exp Psychol Anim Behav Process 5: 368-378.

Bouton ME, Bolles RC (1979b). Contextual control of the extinction of conditioned fear. Learn Motiv 10: 445-466.
Bouton ME, Westbrook RF, Corcoran KA, Maren S (2006). Contextual and temporal modulation of extinction: behavioral and biological mechanisms. Biol Psychiatry 60: 352-360.

Brooks DC, Bouton ME (1994). A retrieval cue for extinction attenuates response recovery (renewal) caused by a return to the conditioning context. J Exp Psychol Anim Behav Process 20: 366-379.

Bruce SE, Yonkers KA, Otto MW, Eisen JL, Weisberg RB, Pagano M et al (2005). Influence of psychiatric comorbidity on recovery and recurrence in generalized anxiety disorder, social phobia, and panic disorder: a 12-year prospective study. Am J Psychiatry 162: 1179-1187.

Fanselow MS (1980). Conditional and unconditional components of postshock freezing. Pavlov J Biol Sci 15: 177-182.

Gomez-Pinilla F, Vu L, Cotman CW (1995). Regulation of astrocytes proliferation by FGF-2 and heparin sulphate in vivo. J Neurosci 15: 2021-2029.

Graham BM, Richardson R (2009a). Acute systemic fibroblast growth factor-2 enhances long-term memory in developing rats. Neurobiol Learn Mem 91: 424-430.

Graham BM, Richardson R (2009b). Acute systemic fibroblast growth factor-2 enhances long-term extinction of fear and reduces reinstatement in rats. Neuropsychopharmacology 34: 1875-1882.

Guastella AJ, Richardson R, Lovibond PF, Rapee RM, Gaston JE, Mitchell $\mathrm{P}$ et al (2008). A randomized controlled trial of D-cycloserine enhancement of exposure therapy for social anxiety disorder. Biol Psychiatry 63: 544-549.

Gunther LM, Denniston JC, Miller RR (1998). Conducting exposure treatment in multiple contexts can prevent relapse. Behav Res Ther 36: 75-91.

Hofmann SG, Meuret AE, Smits JA, Simon NM, Pollack MH, Eisenmenger $\mathrm{K}$ et al (2006). Augmentation of exposure therapy with D-cycloserine for social anxiety disorder. Arch Gen Psychiatry 63: 298-304.

Kim JH, Richardson R (2008). The effect of temporary amygdala inactivation on extinction and reextinction of fear in the developing rat: unlearning as a potential mechanism for extinction in early development. J Neurosci 28: 1282-1290.

Kushner MG, Kim SW, Donahue C, Thuras P, Adson D, Kotlyar M et al (2007). D-cycloserine augmented exposure therapy for obsessive-compulsive disorder. Biol Psychiatry 62: 835-838.

Lederman RJ, Mendelsohn FO, Anderson RD, Saucedo JF, Tenaglia AN, Hermiller JB et al (2002). Therapeutic angiogenesis with recombinant fibroblast growth factor-2 for intermittent claudication (the TRAFFIC study) randomised trial. Lancet 359: 2053-2058.

Ledgerwood L, Richardson R, Cranney J (2003). Effects of D-cycloserine on extinction of conditioned freezing. Behav Neurosci 117: 341-349.

Ledgerwood L, Richardson R, Cranney J (2004). D-cycloserine and the facilitation of extinction of conditioned fear: consequences for reinstatement. Behav Neurosci 118: 505-513.

McNally RJ (2007). Mechanisms of exposure therapy: how neuroscience can improve psychological treatments for anxiety disorders. Clin Psych Rev 27: 750-759.

Mineka S, Mystkowski JL, Hladek D, Rodriguez BI (1999). The effects of changing context on return of fear following exposure therapy for spider fear. J Consulting Clin Psychol 67: 599-604.

Monfils MH, Cowansage KK, Klann E, LeDoux JE (2009). Extinction-reconsolidation boundaries: key to persistent attenuation of fear memories. Science 324: 951-955.

Myers KM, Davis M (2007). Mechanisms of fear extinction. Mol Psychiatry 12: 120-150.

Mystkowski JL, Craske MG, Echiverri AM (2002). Treatment context and return of fear in spider phobia. Behav Ther 33: 399-414.

Parnas SA, Weber M, Richardson R (2005). Effects of multiple exposures to D-cycloserine on extinction of conditioned fear in rats. Neurobiol Learn Mem 83: 224-231. 
Perez JA, Clinton SM, Turner CA, Watson SJ, Akil H (2009). A new role for FGF2 as an endogenous inhibitor of anxiety. J Neurosci 29: 6379-6397.

Quirk GJ, Mueller D (2008). Neural mechanisms of extinction learning and retrieval. Neuropsychopharmacol Rev 33: 56-72.

Ressler KJ, Rothbaum BO, Tannenbaum L, Anderson P, Graap K, Zimand $\mathrm{E}$ et al (2004). Cognitive enhancers as adjuncts to psychotherapy: use of D-cycloserine in phobic individuals to facilitate extinction of fear. Arch Gen Psychiatry 61: 1136-1144.

Turner CA, Gula EL, Taylor LP, Watson SJ, Akil H (2008). Antidepressant-like effects of intracerebroventricular FGF2 in rats. Brain Res 1224: 63-68.

Wagner JP, Black IB, DiCicco-Bloom E (1999). Stimulation of neonatal and adult brain neurogenesis by subcutaneous injection of basic fibroblast growth factor. J Neurosci 19: 6006-6016.

Walicke PA, Cowan WM, Ueno N, Baird A, Guillemin R (1986). Fibroblast growth factor promotes survival of dissociated hippocampal neurons and enhances neurite extension. Proc Natl Acad Sci USA 83: 3012-3016.

Walker DL, Ressler KJ, Lu KT, Davis M (2002). Facilitation of conditioned fear extinction by systemic administration or intraamygdala infusions of D-cycloserine as assessed with fearpotentiated startle in rats. J Neurosci 22: 2343-2351.

Werner-Seidler A, Richardson R (2007). Effects of D-cycloserine on extinction: consequences of prior exposure to imipramine. Biol Psychiatry 62: 1195-1197.

WHO (2001). The World Health Report 2001: Mental Health: New Understanding, New Hope. Geneva: World Health Organisation.

Woods MA, Bouton ME (2006). D-Cycloserine facilitates extinction but does not eliminate renewal of the conditioned emotional response. Behav Neurosci 120: 1159-1162.

Yuzaki M, Furuichi K, Mikoshiba K, Kagawa Y (1994). A stimulus paradigm inducing long-term desensitization of AMPA receptors evokes a specific increase in BDNF mRNA incerebellar slices. Learn Memory 1: 230-242. 